\title{
Analyzing airflow in static ice caves by using the calcFLOW method
}

\author{
Christiane Meyer ${ }^{1}$, Ulrich Meyer ${ }^{2}$, Andreas Pflitsch ${ }^{3}$, and Valter Maggi ${ }^{1}$ \\ ${ }^{1}$ Universita di Milano-Bicocca, Dipartimento di Scienze Ambiente e Territorio e Scienze della Terra, Piazza della Scienza 1, \\ 20126 Milan, Italy \\ ${ }^{2}$ University of Bern, Astronomical Institute, Sidlerstrasse 5, 3012 Bern, Switzerland \\ ${ }^{3}$ Ruhr-University Bochum, Geography Department, Working Group Cave- and Subway-Climatology, Universitätsstrasse \\ 150/Building NA, 44780 Bochum, Germany
}

Correspondence to: C. Meyer (christianemeyer@gmx.ch)

Received: 29 July 2015 - Published in The Cryosphere Discuss.: 30 September 2015

Revised: 29 March 2016 - Accepted: 13 April 2016 - Published: 25 April 2016

\begin{abstract}
In this paper we present a method to detect airflow through ice caves and to quantify the corresponding airflow speeds by the use of temperature loggers. The time series of temperature observations at different loggers are crosscorrelated. The time shift of best correlation corresponds to the travel time of the air and is used to derive the airflow speed between the loggers. We apply the method to test data observed inside Schellenberger Eishöhle (ice cave). The successful determination of airflow speeds depends on the existence of distinct temperature variations during the time span of interest. Moreover the airflow speed is assumed to be constant during the period used for the correlation analysis. Both requirements limit the applicability of the correlation analysis to determine instantaneous airflow speeds. Nevertheless the method is very helpful to characterize the general patterns of air movement and their slow temporal variations. The correlation analysis assumes a linear dependency between the correlated data. The good correlation we found for our test data confirms this assumption. We therefore in a second step estimate temperature biases and scale factors for the observed temperature variations by a least-squares adjustment. The observed phenomena, a warming and an attenuation of temperature variations, depending on the distance the air traveled inside the cave, are explained by a mixing of the inflowing air with the air inside the cave. Furthermore we test the significance of the determined parameters by a standard $F$ test and study the sensitivity of the procedure to common manipulations of the original observations like smoothing. In the end we will give an outlook on possible applications and further development of this method.
\end{abstract}

\section{Introduction}

Ice cave research in its historical dimension has a long history in Europe (Grebe, 2010), which dates back to the 16th century. Theories about the origin of the cave ice are equally old, numerous, and contradictory, depending on the scientific knowledge and ability to conduct measurements in the respective century. In the nineteenth century the first instrumental measurements were conducted (compare Thury, 1861; Fugger, 1888; Lohmann, 1895; Crammer, 1899) before modern ice cave research found its beginning with the works of, e.g., Bock (1913), Racovitza (1927), Saar (1956), and others. Evidently, right from the beginning the main focus was to understand the processes and dynamics of the ice body and specific cave climate elements; among those, the course of the air temperature in the specific study sites as well as the airflow regime were a main focus. Until today longterm measurements have been rare but do exist in several European commercial caves, e.g., Scarisoara ice cave (Racovitza and Onac, 2000), Dachstein Rieseneishöhle (Saar, 1956), Dobsinska ice cave (Korzystka et al., 2011), and Schellenberger Eishöhle (Meyer et al., 2014). In addition, short-term measurements are conducted by speleological organizations and others at many sites, thus covering numerous ice cave sites worldwide. The full potential of these study sites and recorded data has not yet been exploited. Most climate studies in ice caves concentrate on air, ice, and rock temperature, as temperature loggers are available for relatively low prices and thus also affordable for private studies by, e.g., speleological organizations. Depending on the individual questioning, this may be sufficient for a basic cave climate analy- 
sis. Besides financial reasons, ice cave studies are facing two other problems in general: the accessibility of the study site and the energy supply for technical devices. The study sites are in many cases in remote places in the high mountains, exposed to avalanches and winter conditions often lasting several months. As a consequence, e.g., airflow measurements using sonic anemometers are not always possible, though an understanding of the airflow regime is indispensable for the understanding of these complex systems (e.g., Pflitsch and Piasecki, 2003). For the development but also degradation of subterranean ice, the airflow regime is the main influencing factor beside the time/amount of water and the thermal conditions or the heat transfer between the different media (rock, ice, water, air) (Korzystka et al., 2011). Racovitza (1927) states that the main factor that characterizes a cave in general is the air temperature. Among the deduced topoclimatological factors, the airflow regime, which is first of all determined by the thermal relation between the exterior atmosphere and the cave atmosphere, is the most important physical factor to describe the topoclimate of a cave. For this reason Racovitza (1975) proposes to classify the different types of cave topoclimate using the diverse types of airflow regimes. Lütscher and Jeannin (2004a) propose, for the specific case of ice caves in temperate regions, to classify on the basis of two criteria: cave air dynamics and the type of ice. They explain this by the importance of the airflow regime as the "dominating process at the origin of cave ice" in, e.g., static or dynamic ice caves, just to mention the best known ice cave types. Numerous case studies highlight the role of airflow for the development of ice caves, (e.g., Lütscher and Jeannin, 2004b; Pflitsch et al., 2007; Morad et al., 2010). For these reasons we present here calcFLOW, a practical attempt to use the database which is available for the majority of ice caves, i.e., air temperature measurements for computing air fluxes. In this paper we present the basic principles and the methodology of the calcFLOW method and apply it to Schellenberger Eishöhle (Germany). The results allow the interpretation of observations that have so far not been well understood, but also reveal principle shortcomings of the setup of the loggers that limit the analysis. They will be useful to install a refined network of temperature loggers inside the cave. We are convinced that also other observation campaigns may benefit from analysis by the calcFLOW method. In the last part of this paper possible further applications of the calcFLOW method are discussed. All calculations were conducted by using the GNU Octave open-source software ${ }^{1}$.

\section{Study site and data}

Bögli (1978) defined ice caves as caves containing ice all year around. One can further distinguish different types

${ }^{1}$ https://www.gnu.org/software/octave/ based on the origin of the ice, the main ice building processes, and the type of the ventilation (Lütscher, 2005). Ice caves occur mainly at elevations below the $0{ }^{\circ} \mathrm{C}$ isotherm (in the Alps at about $2000 \mathrm{~m}$ elevation) due to the availability of water, but they may also occur in permafrost regions (Lütscher and Jeannin, 2002). Boundary criteria, which additionally limit the existence of ice caves are the airflow system, the number of surface openings, and the cave morphology. One common type are the static ice caves. Like in our example, this kind of ice cave only has one natural entrance, which is situated in the upper or middle part of the cave, and therefore acts like a cold air trap. In summer, when outside temperatures are above the cave air temperatures, the cooler air stays in the cold air trap and is only slowly warmed by the surrounding rock. Stable temperature stratification occurs when deep temperatures are preserved over summer. The open phase or so-called "winter situation", when air exchange with the external atmosphere occurs, is limited to external temperatures below the cave air temperatures. When outside temperatures drop below the current cave air temperature, the colder air replaces the warm air inside the cave. The cold air enters the cave along the floor of the cave passages, while the warm air is pushed out along the ceiling towards the cave entrance. The temperatures observed close to the cave floor and at the ceiling therefore may differ greatly. For this reason care has to be taken in the selection of the positions for the temperature loggers to capture the airflow of interest. By the mixing of cold and warm airflows and by the contact of the inflowing cold air with the cave walls and cave ice, the inflowing air will gradually warm up, and on the other hand, the cave is cooled down from the entrance towards its inner reaches. As a consequence the stratification of the cave air is disturbed. Instead, the air temperature positively correlates with the distance the air traveled inside the cave. Temperatures recorded along the floor of descending passages that track the inflowing cold air will show an inverted gradient compared to temperatures observed during the closed phase. As soon as the outside temperatures rise above the cave temperature and the inflow of cold air stops the stratification of the air is restored.

To illustrate the calcFLOW method we apply it to temperature data collected in Schellenberger Eishöhle located on Untersberg (Germany). Untersberg is an isolated mountain in the most northern part of the Berchtesgaden Alps (Northern Limestone Alps) at the border between Austria and Germany (Fig. 1). Schellenberger Eishöhle is a big alpine cave (total length: $3621 \mathrm{~m}$, total depth: $+39,-221 \mathrm{~m}$ ), including a static ice cave part which has been run as a show cave since 1925 . Apart from the $500 \mathrm{~m}$ long ice cave part, there is one major non-ice part, which forks off close to the entrance in a northeasterly direction and leads through several deep shafts to the deepest point of the cave $(-221 \mathrm{~m})$. The cave is situated at $1570 \mathrm{ma.s.l}$. at the foot of the eastern walls of Untersberg (the cave entrance is marked in Fig. 1). The access to the cave is by a $4 \mathrm{~m}$ high and $20 \mathrm{~m}$ wide portal, which leads to 

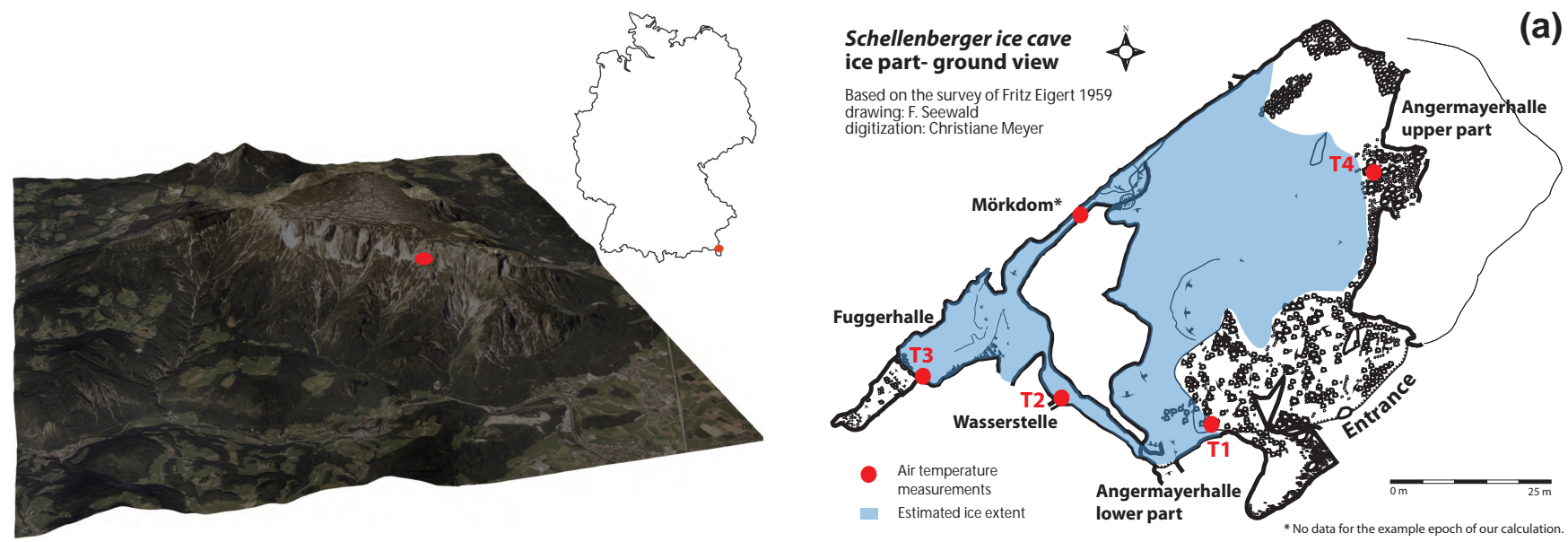

Figure 1. Location of Schellenberger Eishöhle at the foot of the east face of Untersberg. The mountain is viewed from the East, the length of the edges is $11 \mathrm{~km}$ (orthophotos: ${ }^{\circ}$ 2003/2004, Salzburg AG and DI Wenger-Oehn, digital elevation model: Bundesamt für Eich- und Vermessungswesen in Wien). The map inlay shows the location of Untersberg in Germany.

Josef-Ritter-von-Angermayer-Halle, the largest room in the cave with a length of $70 \mathrm{~m}$ and a width of $40 \mathrm{~m}$, that is illuminated by daylight. The floor of this hall, $17 \mathrm{~m}$ below the entrance level, completely consists of a major ice monolith, which is surrounded by the cave trail. The two passages Wasserstelle and Mörkdom connect to the deepest part of the ice cave called Fuggerhalle, $41 \mathrm{~m}$ below entrance level. They are also partly covered with ice. Temperature loggers were placed in Angermayerhalle (T1 and T4), along one of the passages leading downwards (Wasserstelle: T2), and in Fuggerhalle (T3, see Fig. 2). The loggers recorded temperature data with an interval of 10 resp. $15 \mathrm{~min}$. These temperature measurements were recorded for a first cave climate study of Schellenberger ice cave (compare Meyer et al., 2014; Grebe et al., 2008) and the logger setup was not optimized for the application of the calcFLOW method. Therefore synchronizing the sampling rates of the different loggers was not emphasized. Analyzing the observed temperature data, several questions arose. The two loggers in Angermayerhalle show quite different temperature behavior that could not easily be explained. Moreover the logger in Fuggerhalle recorded temperatures that seemed to be too warm for the lowest part of the ice cave where the coldest air was expected. The development of the calcFLOW method was motivated by these observations and led to reasonable explanations for the observed phenomena.

\section{The model}

As described in Sect. 2, two different stages of a static ice cave have to be distinguished: an open and a closed phase.

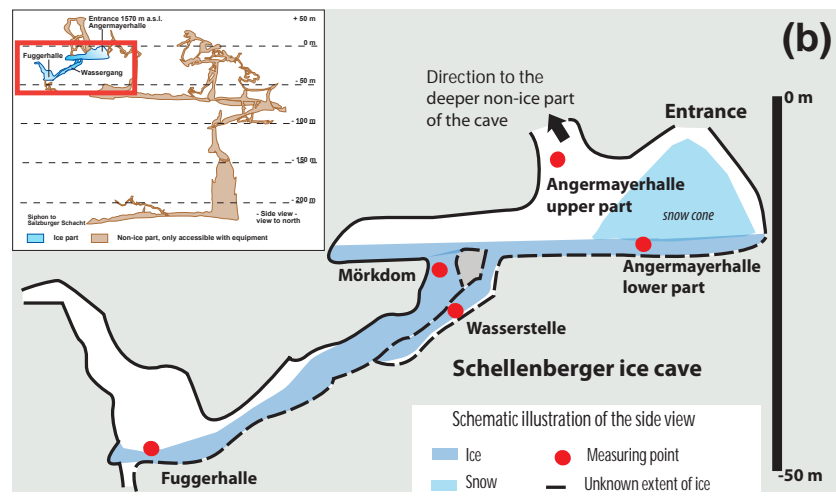

Figure 2. Ground map and side view of Schellenberger Eishöhle with positions of all temperature loggers.

During the closed phase, or so-called "summer situation", the air temperature in the cave is below the temperature outside and no interaction between the inside and outside atmosphere by gravitational air mass transport takes place. In this case the undisturbed air inside the cave shows stratification due to its specific weight, the densest (coldest) air occupying the deepest ranges of the cave. As long as the slow warming of the cave during the closed phase is ignored, the difference in temperature observed by two loggers at different locations in the cave is constant over time and may be described by a simple bias:

$T_{\mathrm{B}}(t)=T_{\mathrm{A}}(t)+b$,

$T_{\mathrm{A}}$ and $T_{\mathrm{B}}$ being the temperatures observed at time $t$ by the loggers at locations A and B inside the cave. $b$ is the temperature bias observed between both loggers and is considered to be constant over time in this simple model. The phenomenon of stratification of air in static ice caves during the closed phase is a basic principle and is not discussed further here.

Instead we focus on the open phase, the so-called "winter situation" that is most relevant for the cooling of the cave and therefore for the existence of the cave ice. During the open phase, loggers at different locations in the cave will record 
a completely different scenario than during the closed phase. We expect a temperature bias, but now with inverted sign, the cave being warmer the further inside the logger is placed (see Sect. 2). We furthermore expect the variations in air temperature that are driven by the weather and the day/night cycle outside the cave to be measurable also inside the cave, but attenuated, due to mixing of the inflowing air with the more stagnant air inside the cave. Thirdly, we assume that the cold inflowing air needs some time to travel from logger A to logger B. Our model for the air temperature measurements taken by different loggers during the open phase of a static ice cave includes all three parameters: bias, scale factor (attenuation of temperature variations), and travel time of the air from logger A to logger B. The model for the open phase therefore reads

$$
T_{\mathrm{B}}(t)-\bar{T}_{\mathrm{B}}=s \cdot\left(T_{\mathrm{A}}(t-\Delta t)-\bar{T}_{\mathrm{A}}\right) .
$$

$T_{\mathrm{A}}, T_{\mathrm{B}}$, and $t$ are defined as above. The model is augmented by a scale factor $s$ and the travel time $\Delta t$ of the air moving from logger $\mathrm{A}$ to logger $\mathrm{B}$. In fact $\Delta t$ is the parameter ultimately of most interest to calculate the speed of air flow between loggers. $\bar{T}_{\mathrm{A}}$ and $\bar{T}_{\mathrm{B}}$ are the mean temperatures measured by loggers $\mathrm{A}$ and $\mathrm{B}$. The terms $T_{\mathrm{B}}(t)-\bar{T}_{\mathrm{B}}$ and $T_{\mathrm{A}}(t-\Delta t)-\bar{T}_{\mathrm{A}}$ describe the temperature variations around the means recorded by the two loggers, that are attenuated by factor $s$ at logger B due to the mixing of the inflowing air with stagnant air along the way from logger A to logger B. The bias $b=\bar{T}_{\mathrm{B}}-\bar{T}_{\mathrm{A}}$ is hidden in the difference between the mean temperatures at $\mathrm{A}$ and $\mathrm{B}$.

We express the temperature modeled for logger $\mathrm{B}$ as a function of the temperature measured by logger A:

$T_{\mathrm{B}}(t)=s \cdot\left(T_{\mathrm{A}}(t-\Delta t)-\bar{T}_{\mathrm{A}}\right)+b^{*}, b^{*}=\bar{T}_{\mathrm{B}}=\bar{T}_{\mathrm{A}}+b$.

The parameters $b^{*}$ and $s$ of this simple model may be estimated from the observed temperature data by a standard least-squares adjustment process (Koch, 1999). To keep things simple, the single temperature measurements are assumed to be independent of each other and not affected by colored noise (i.e., their errors are assumed to be normally distributed).

To set up the design matrix $\mathbf{A}$ of the adjustment process we have to compute the partial derivatives of the modeled temperatures at $\operatorname{logger} B$ with respect to the unknown parameters $b^{*}$ and $s$ :

$$
\begin{aligned}
\mathbf{A} & =\left(\begin{array}{cc}
\frac{\partial T_{\mathrm{B}}\left(t_{1}\right)}{\partial b^{*}} & \frac{\partial T_{\mathrm{B}}\left(t_{1}\right)}{\partial s} \\
\vdots & \vdots \\
\frac{\partial T_{\mathrm{B}}\left(t_{n}\right)}{\partial b^{*}} & \frac{\partial T_{\mathrm{B}}\left(t_{n}\right)}{\partial s}
\end{array}\right), \frac{\partial T_{\mathrm{B}}(t)}{\partial b^{*}}=1, \frac{\partial T_{\mathrm{B}}(t)}{\partial s} \\
& =T_{\mathrm{A}}(t-\Delta t)-\bar{T}_{\mathrm{A}} .
\end{aligned}
$$

The optimal solutions $\hat{b}^{*}$ and $\hat{s}$ of the sought-for parameters are found by solving the equation

$$
\left(\begin{array}{c}
\hat{b}^{*} \\
\hat{s}
\end{array}\right)=\left(\mathbf{A}^{T} \mathbf{P A}\right)^{-1} \mathbf{A}^{T} \mathbf{P} \boldsymbol{T}_{\mathrm{B}}
$$

where $\boldsymbol{T}_{\mathrm{B}}$ is the column vector of temperatures measured at logger B. The weight matrix $\mathbf{P}$ is the identity matrix, as long as all temperatures are observed with comparable quality (otherwise it is a diagonal matrix with the diagonal elements equal to the inverse of the square of the assumed a priori errors). With the estimated parameters $\hat{b}^{*}$ and $\hat{s}$ the difference between observed and modeled temperatures at logger $\mathrm{B}$, determined by the sum of squares of the residuals, is minimized.

To determine the third unknown parameter $\Delta t$ in the same way, we would have to compute the partial derivative:

$$
\frac{\partial \boldsymbol{T}_{\mathrm{B}}}{\partial \Delta t}=\frac{\partial \boldsymbol{T}_{\mathrm{B}}}{\partial \boldsymbol{T}_{\mathrm{A}}} \frac{\partial \boldsymbol{T}_{\mathrm{A}}}{\partial \Delta t}=s \cdot \frac{\partial \boldsymbol{T}_{\mathrm{A}}}{\partial \Delta t} .
$$

Neither an a priori value for $s$ nor $\partial \boldsymbol{T}_{\mathrm{A}} / \partial \Delta t$ are known. We therefore propose to determine the time shift $\Delta t$ independently by cross-correlation of the time series of observed temperatures $\boldsymbol{T}_{\mathrm{A}}$ and $\boldsymbol{T}_{\mathrm{B}}$.

The correlation between cave and outside temperatures to our knowledge was first studied by Smithson (1991), who did not take into account time shifts between different logger sites. The idea behind the correlation analysis presented here is that a weather-induced temperature pattern is visible at all measuring stations inside the cave and that it is sufficiently unique to produce a distinct maximum of correlation when cross-correlating the observed temperature time series of two different loggers. For this purpose one of the time series is shifted in time until maximum correlation is reached. The time shift corresponding to optimal correlation of both time series is equal to the travel time of the air between the two temperature loggers. To determine the airflow speed, the length of the passage between the two loggers has to be divided by the travel time of the air. An analogous method is used, e.g., in hydrology to determine the travel time of a flood pulse or, when applied to karst springs, the time delay between rainfall and discharge (see, e.g., Padilla and PulidoBosch, 1994; Laroque et al., 1998). In case of hydrology the medium is water, not air, and the observable is the flow rate, not the temperature.

Pearson's correlation coefficient between two linearly correlated time series $X$ and $Y$ of $n$ samples each is computed by

$$
r=\frac{\sum_{i=1}^{n}\left(x_{i}-\bar{x}\right)\left(y_{i}-\bar{y}\right)}{\sqrt{\sum_{i=1}^{n}\left(x_{i}-\bar{x}\right)^{2}} \sqrt{\sum_{i=1}^{n}\left(y_{i}-\bar{y}\right)^{2}}},
$$

where $\bar{x}=1 / n \sum_{i=1}^{n} x_{i}$ and $\bar{y}=1 / n \sum_{i=1}^{n} y_{i}$ are the mean values of the corresponding time series. The correlation coefficient $r$ will take values between -1 and 1 . A value of 1 


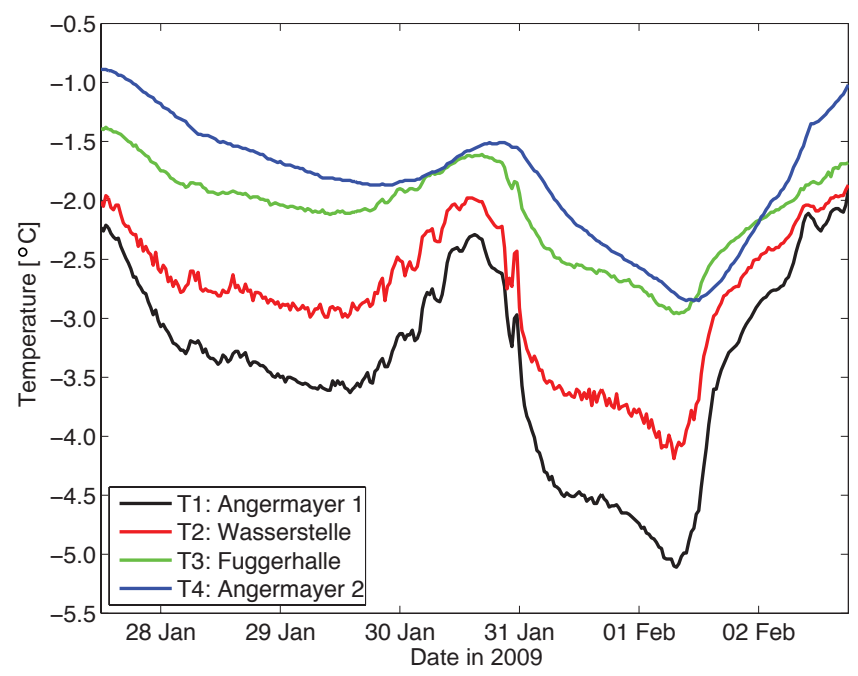

Figure 3. Temperature observations of loggers T1 (Angermayerhalle, lower part), T2 (Wasserstelle), T3 (Fuggerhalle), and T4 (Angermayerhalle, upper part) available for analysis.

validates the assumption that $Y=b+s \cdot X$ with bias $b$ and scale $s$. Note that this assumption exactly corresponds to our simple model introduced above, and therefore $r$ may additionally serve to validate the applicability of the model.

\section{Application to data}

To illustrate the methods introduced in Sect. 3, we apply them to temperature measurements recorded in the static ice cave Schellenberger Eishöhle. In Fig. 3, temperature observations of the four different loggers are displayed for a period of 6 days. During this period, a gradual cooling can be observed during the first 5 days, interrupted by a warm spell on 30 January. On 1 February warmer weather sets in, resulting in a rather abrupt rise in cave temperatures. As mentioned in Sect. 2, the loggers recorded temperature observations at either 10 or $15 \mathrm{~min}$ intervals. For our analysis observations at common $30 \mathrm{~min}$ intervals were chosen. It turned out that for the determination of wind speeds, a higher sampling rate would have been beneficial. It therefore is planned to synchronize and increase the sampling rate in the future.

In a first step, time shifts between one of the loggers in Angermayerhalle (T1) and all the other loggers (T2, T3, and T4) were determined for an example epoch early in the afternoon of 30 January, applying the correlation analysis. In a second step, temperature biases and scale factors between the corresponding loggers were determined from the same set of data according to the least-squares formalism introduced in Sect. 3.

\subsection{Correlation analysis}

Two parameters have to be chosen carefully when actually correlating the temperature data. First we have to define the number $n$ of samples we want to use for correlation. We inherently assume that the airflow speed is constant for the time period covered by the $n$ samples. It is therefore desirable to choose $n$ as small as possible if we are interested in the temporal variability of the airflow speed in the cave. On the other hand the part of the time series under consideration has to be long enough to show a unique temperature pattern for correlation. Due to the smoothness of the observed temperatures they will resemble a linear trend during short stretches of time. Cross-correlating two straight lines will produce constant correlation coefficients of 1 , and no distinct maximum will be distinguishable.

To find an adequate $n$ it is helpful to actually take a look at the correlation function of example data observed in Schellenberger Eishöhle. We analyzed temperatures observed by four different loggers during periods of large temperature variations on 30 January (Fig. 4) or small temperature variations on 29 January (Fig. 5). The temperatures at logger T1 were taken as a reference, while the temperatures recorded by loggers $\mathrm{T} 2, \mathrm{~T} 3$, and $\mathrm{T} 4$ were cross-correlated with the temperatures at logger T1 using different numbers of samples. During periods with large temperature variations, only a small number of samples is needed to produce distinctive maxima in the correlation function (Fig. 4, bottom panels). Actually for our example epoch, correlation maxima are more distinctive the fewer samples are used. During periods of little temperature variations on the other hand, no distinction of a maximum of correlation is possible, if too few samples $n$ are considered for cross-correlation (Fig. 5, middle and bottom panels) and the determined time shifts become meaningless. Generally we may assume that a time span of 1 day (corresponding roughly to a correlation length $n$ of 51 samples in Figs. 4 and 5) will most probably suffice in most cases to get a clear correlation peak due to the day/night cycle in outside temperature. Shorter time spans may suffice during periods of pronounced weather patterns. Fine tuning of $n$ will be worthwhile, whenever time resolution of the determined airflow speeds is in the center of interest.

The second parameter we have to choose is the maximum number of samples we shift time series $Y$ against time series $X$. From a computational cost point of view, it is desirable to keep this number small. Moreover, periodic temperature patterns like the day/night cycle will lead to secondary maxima in the correlation function, if we shift one time series by a full period of the cycle (i.e., 1 day). A rough idea of the expected airflow speeds is helpful to adjust this parameter. If the air is expected to move within $10 \mathrm{~min}$ from logger A to $\log g e r \mathrm{~B}$, it is in principle not necessary to shift the time series at logger $\mathrm{B}$ by more than 10 min to catch the maximum in the correlation function. In our examples we used time win- 

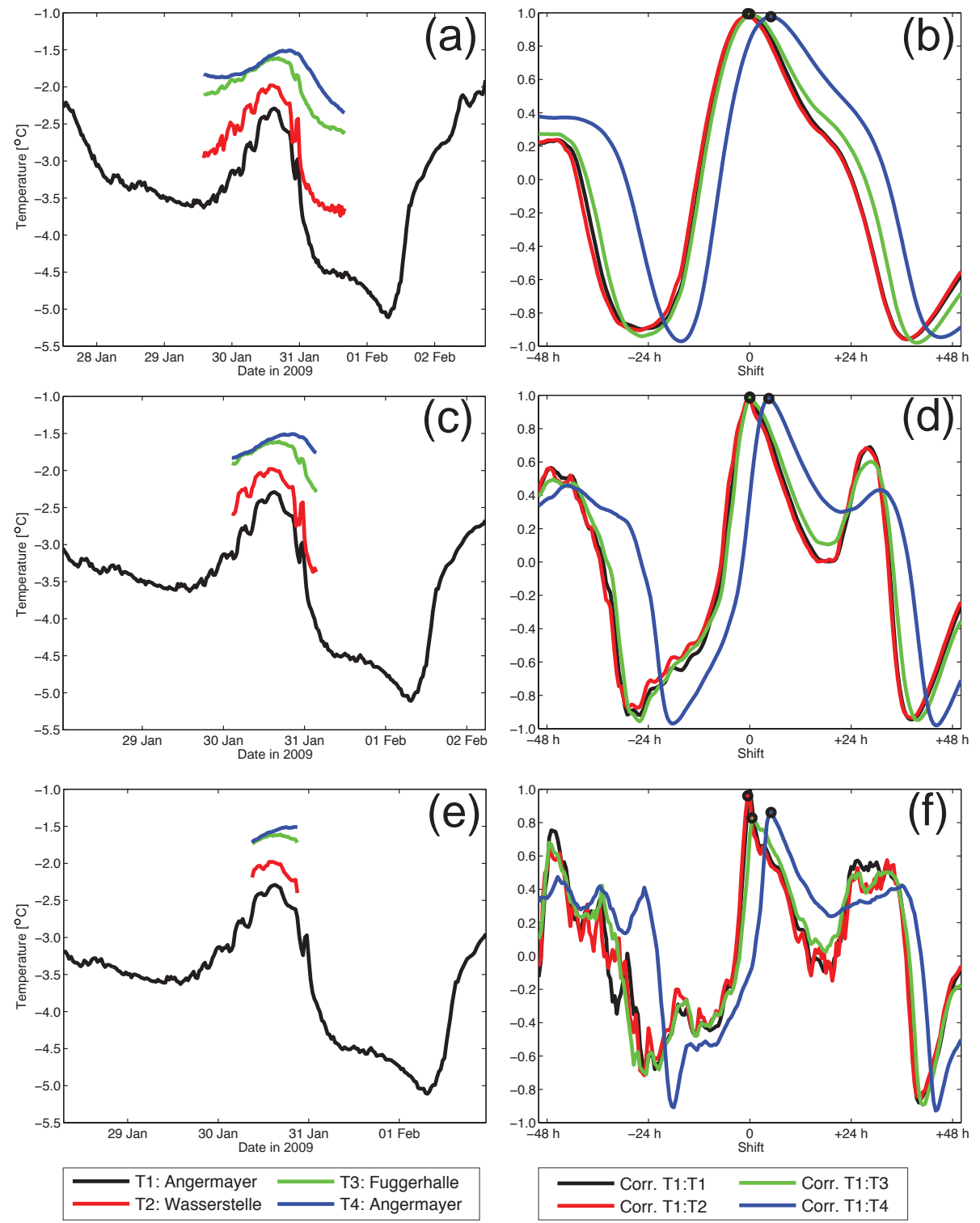

Figure 4. Observed temperatures (left panels) and correlation functions (right panels) during a period of large temperature variations, well suited for correlation analysis. Data of loggers T2, T3, or T4 are cross-correlated with the data of logger T1 using a correlation length of $101(\mathbf{a}, \mathbf{b}), 51(\mathbf{c}, \mathbf{d})$, and 25 (e, f) samples.

dows of $\pm 2 \mathrm{~d}$ to also show the variability of the correlation coefficient related to the applied time shift.

It has to be stressed that the sampling rate of the temperature measurements limits the time resolution of the correlation analysis. The time shift of maximum correlation will always be an integer multiple of the sampling rate, and its uncertainty corresponds to half the sampling rate. Even if the smooth nature of the temperature measurements suggests increasing the sampling rate by interpolation, this will not introduce new information for the correlation analysis. On the other hand, it does not disturb the analysis according to our experience (not shown).

\subsection{Bias and scale}

The time shifts determined by the correlation analysis are inserted into Eq. (4) to compute the partial derivatives with respect to the scale factors. In a consecutive step, biases and scale factors of our simple model can be determined for each pair of data loggers. We perform the least-squares adjustment for the example epoch of Fig. 4, applying the time shifts determined using 51 samples (Fig. 4, middle row).

Figure 6 shows the fit of observations of loggers T2, T3, and T4 to observations of logger T1, Fig. 7, the inverse fit of $\mathrm{T} 1$ to data of either $\mathrm{T} 2, \mathrm{~T} 3$, or T4. Both definitions are valid in principle. The parameters determined for the exam- 

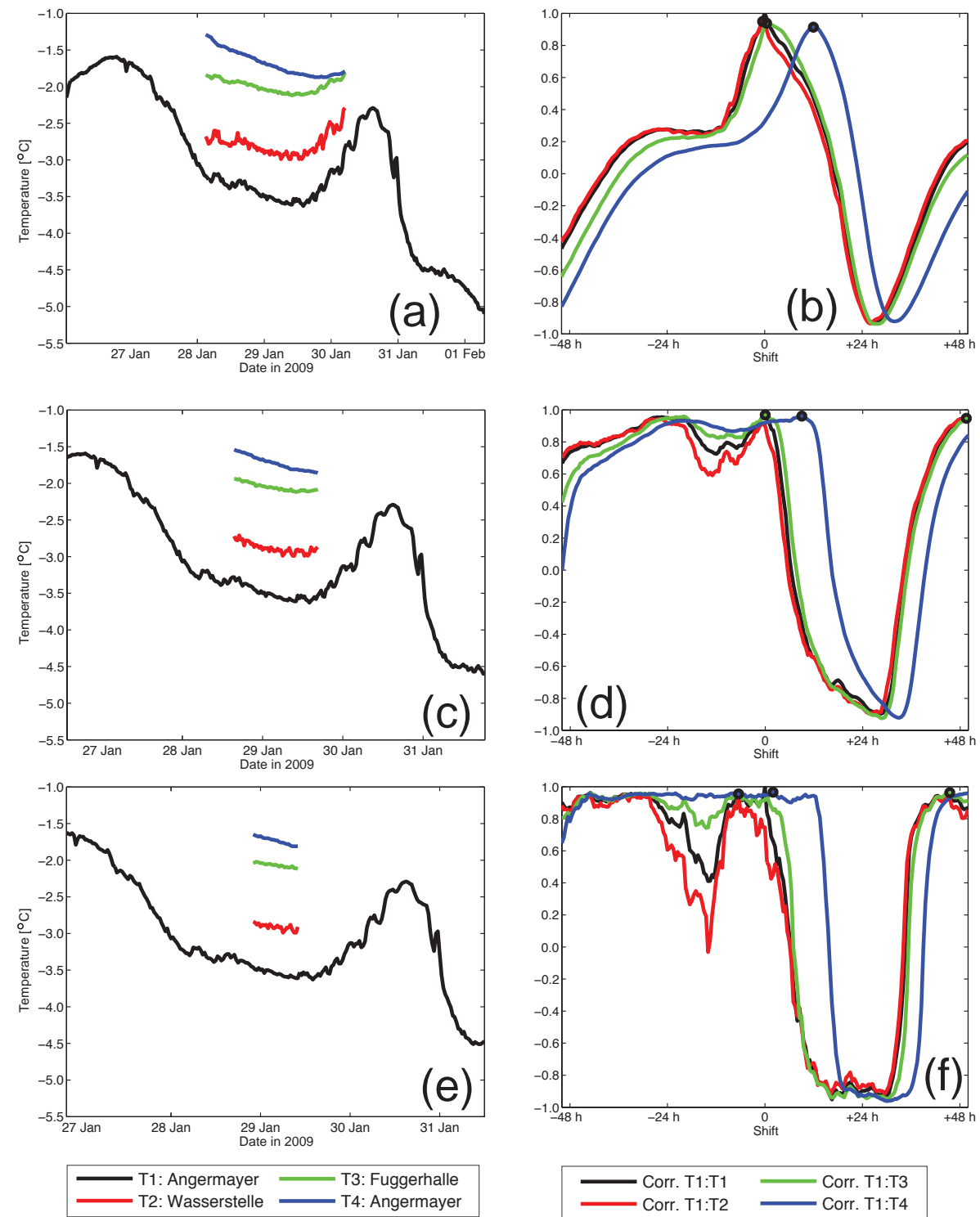

Figure 5. Observed temperatures (left panels) and correlation functions (right panels) during a period of small temperature variations, apparently not so well suited for correlation analysis. Data of loggers T2, T3, or T4 are cross-correlated with the data of logger T1 using a correlation length of $101(\mathbf{a}, \mathbf{b}), 51(\mathbf{c}, \mathbf{d})$, and $25(\mathbf{e}, \mathbf{f})$ samples.

ple epoch are listed in the legends of Figs. 6 and 7. To compare them, the signs of the time shift and bias of either Figs. 6 or 7 have to be changed and the corresponding scale has to be inverted. Note that bias and scale factor were determined together and are only evaluated separately for Figs. 6 and 7.

Between loggers $\mathrm{T} 1$ and $\mathrm{T} 2$ the air is warmed by $0.45^{\circ} \mathrm{C}$ (or $0.47^{\circ} \mathrm{C}$ ); between $\mathrm{T} 1$ to $\mathrm{T} 3$ it is warmed by $1.05^{\circ} \mathrm{C}$, and between $\mathrm{T} 1$ and $\mathrm{T} 4$ by $1.12^{\circ} \mathrm{C}$ (or $1.19^{\circ} \mathrm{C}$ ). This warming goes hand in hand with an attenuation of temperature variations by a factor of 0.77 (or 1/1.22) between $\mathrm{T} 1$ and $\mathrm{T} 2$, by a factor of 0.36 (or $1 / 2.75$ ) between $\mathrm{T} 1$ and $\mathrm{T} 3$, and by a factor of 0.31 (or 1/3.49) between T1 and T4. We therefore assume that the inflowing cold air passes $\mathrm{T} 1$ and $\mathrm{T} 2$ on its way to the deepest reaches of the cave at $\mathrm{T} 3$ and that $\mathrm{T} 4$ records the outflowing warmed air (see Sect. 7 for detailed discussion). For the distance of approximately $65 \mathrm{~m}$ from $\mathrm{T} 1$ to $\mathrm{T} 3$, passing $\mathrm{T} 2$ half way, we get a time shift of $0 \mathrm{~min}$. This means that it took the air less than half the sampling rate, i.e., $15 \mathrm{~min}$ (corresponding to an air speed greater than $4 \mathrm{~m} \mathrm{~min}^{-1}$ ) and that the sampling rate of $30 \mathrm{~min}$ is too infrequent to determine the airflow speed along this way for the example epoch. For the distance of approximately $180 \mathrm{~m}$ from $\mathrm{T} 1$ to T4, assuming that the air passes T1, descends via Wasserstelle (T2), and rises via Mörkdom, we get a time shift of $270 \mathrm{~min}$. Considering only the way from $\mathrm{T} 3$ to $\mathrm{T} 4$ this results in an air speed at the order of $0.5 \mathrm{~m} \mathrm{~min}^{-1}$. The warming of the air along 

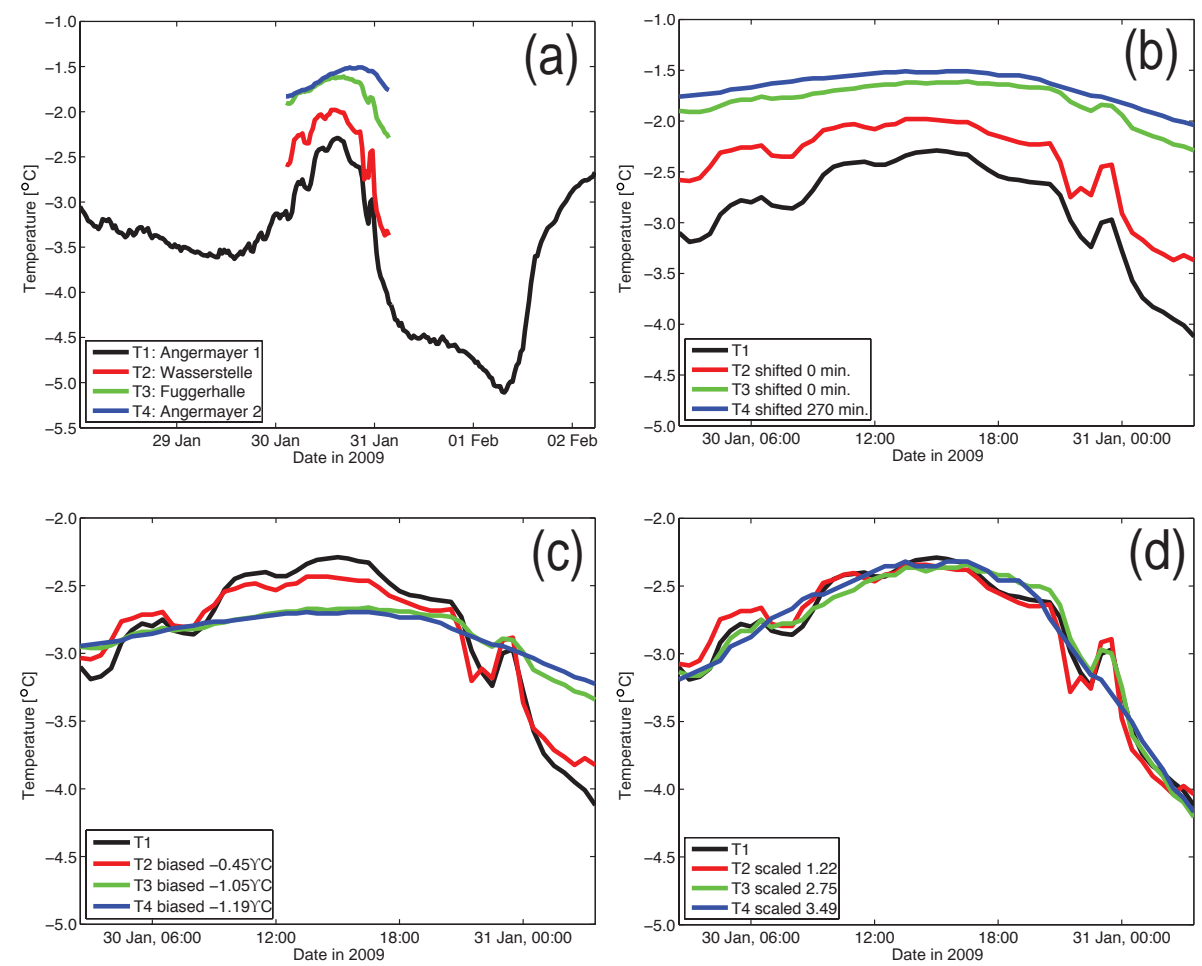

Figure 6. Raw data (a) of loggers $\mathrm{T} 2$, $\mathrm{T} 3$, and $\mathrm{T} 4$ were shifted in time relative to logger $\mathrm{T} 1$ to be correlated (b). The time period shown in (a) corresponds to the search window, while a time span of 51 samples was used for correlation analysis and to adjust temperature biases and scale factors. In a second step (c) the temperature biases were applied to loggers T2, T3, and T4; and finally (d) the temperature variations at loggers T2, T3, and T4 were scaled to fit those at logger T1.

its way through the cave and the attenuation of temperature variations agree well with the assumptions that underlie the model design (see Sect. 3).

The slightly different results in Figs. 6 and 7 are due to the fact that the reference epochs differ by the determined time shifts (depending on which logger is kept fixed as reference). The very much comparable results prove that the method is robust and that the parameters are stable for the period under investigation (the temporal variability of the parameters is studied in Sect. 5). The validity of our model is further confirmed by the optically good fit achieved for the example data (Figs. 6d and 7d); measures for the quality of the model fit are introduced in Sect. 6.

\section{Temporal variability}

In Sect. 4.1 it was mentioned that the airflow speed is supposed to be constant during the time period considered for correlation. In this section we will estimate airflow speeds (time shifts) for the whole period of about 6 days (see Fig. 3) to check if this requirement is met. To do so we repeat the analysis performed in Sect. 4 for an example epoch for all epochs of the period shown in Fig. 3. We use either 51 or 101 samples for correlation. We also try the effect of smooth- ing (by a centered moving mean of five samples) to filter out short-term variations of unknown origin visible in Fig. 3.

The determined time shifts and the corresponding maxima of correlation are displayed in Fig. 8. The latter may serve to assess the reliability of the time shifts. Comparably small correlation coefficients indicate questionable results. Only between loggers T1 and T2 the correlation, at least of the smoothed temperature data, is high during the whole period analyzed and the determined airflow speed is quite constant. As already mentioned, the sampling rate of $30 \mathrm{~min}$ is too coarse to really resolve it; the time shift varies between 0 and $-30 \mathrm{~min}$, indicating a true value between both limits. The negative time shift, which is at first glance puzzling, may hint at the placement of logger T1 too high above the ground. The cold air entering the cave moves along the floor of the passage below $\mathrm{T} 1$ and reaches $\mathrm{T} 2$, before it is recorded by $\mathrm{T} 1$ (see discussion in Sect. 7).

The results of the correlation analysis between loggers $\mathrm{T} 1$ and $\mathrm{T} 3$ indicate that the airflow speed in fact is not constant. The larger time shifts determined for the beginning of the time period correspond to higher temperatures and consequently a less pronounced gravitational airflow. Near the end of the period the temperatures rise so much that the air movement stops, the open period of the ice cave is interrupted, and our model is no longer valid. Consequently the correla- 

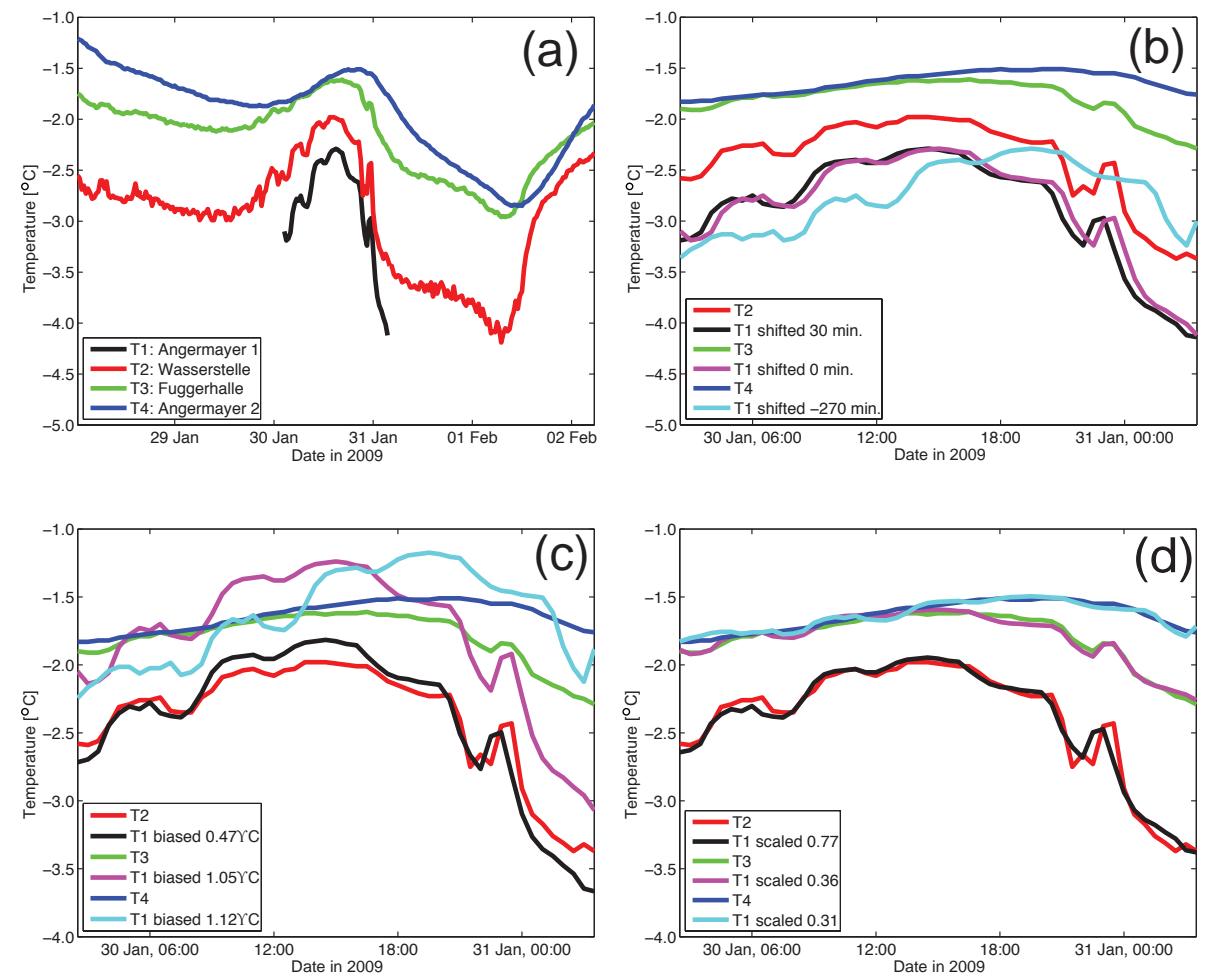

Figure 7. In this example the raw data (a) of logger T1 were shifted (b) relative to loggers T2, T3, or T4 until best correlation was reached. Then (c) temperature biases were applied at logger T1 to fit either T2, T3, or T4 before finally, (d) the temperature variations at logger T1 were scaled to fit loggers $\mathrm{T} 2, \mathrm{~T} 3$, or T4.

tion analysis fails. The somewhat different values determined from the analysis of either 51 or 101 samples indicate that the slow airflow at the beginning of the period affects the results for a longer time if 101 samples are considered for correlation. In general the correlation of a larger number of samples leads to smoother results. In case of the analysis of loggers $\mathrm{T} 1$ and $\mathrm{T} 4$ we get very variable results for the time shifts as well as for the value of maximum correlation. A closer look at the correlation function at single epochs would reveal that side maxima distort the analysis, leading to jumps in the determined time shifts. A reduction of the search window would probably help to remove some of these artifacts. The results achieved for 51 or 101 samples agree best during the middle of the period, where the spell of warm weather leads to a distinct temperature pattern that facilitates the correlation analysis. The smoothing of the data generally improves correlation by reduction of uncorrelated noise, but does not significantly alter the determined time shifts.

After applying the determined time shifts to the time series of temperature observations at loggers $\mathrm{T} 2, \mathrm{~T} 3$, and T4, optimal biases and scale factors were estimated for each epoch. The results are summarized in Fig. 9 and show a strong dependency on the temperature of the cold inflowing air. Colder inflowing air goes hand in hand with larger temperature gradients that lead to a faster inflow of the cold air. This re- sults in less pronounced attenuation of temperature variations, i.e., larger scale factors, because the time for energy exchange with the cave (air, ice, rock) is reduced. The short spell of warm weather on 30 January immediately leads to an increased attenuation, i.e., smaller scale factors. The biases increase with the steepness of the temperature gradients. Again, the parameters were fitted either from 51 temperature samples or from 101 samples. Because the fit is optimal to all samples used, an averaging takes place and the results obtained from more samples look considerably smoother. A smoothing (moving mean) of the temperature time series prior to the estimation of biases and scales helped to derive scales between $\mathrm{T} 1$ and $\mathrm{T} 2$, where short-term variations of unknown origin superimpose the temperature variability induced by outside temperature variation (Fig. 9b).

\section{Validation of the model}

The time shifts derived from the correlation analysis could most easily be validated by actual airflow measurements. However, we do not have airflow measurements available and so we depend on internal validation methods that do not rely on external data. The presented tests allow the plausibility of our model to be validated. The determined correlation coefficients validate the general applicability of the linear model 

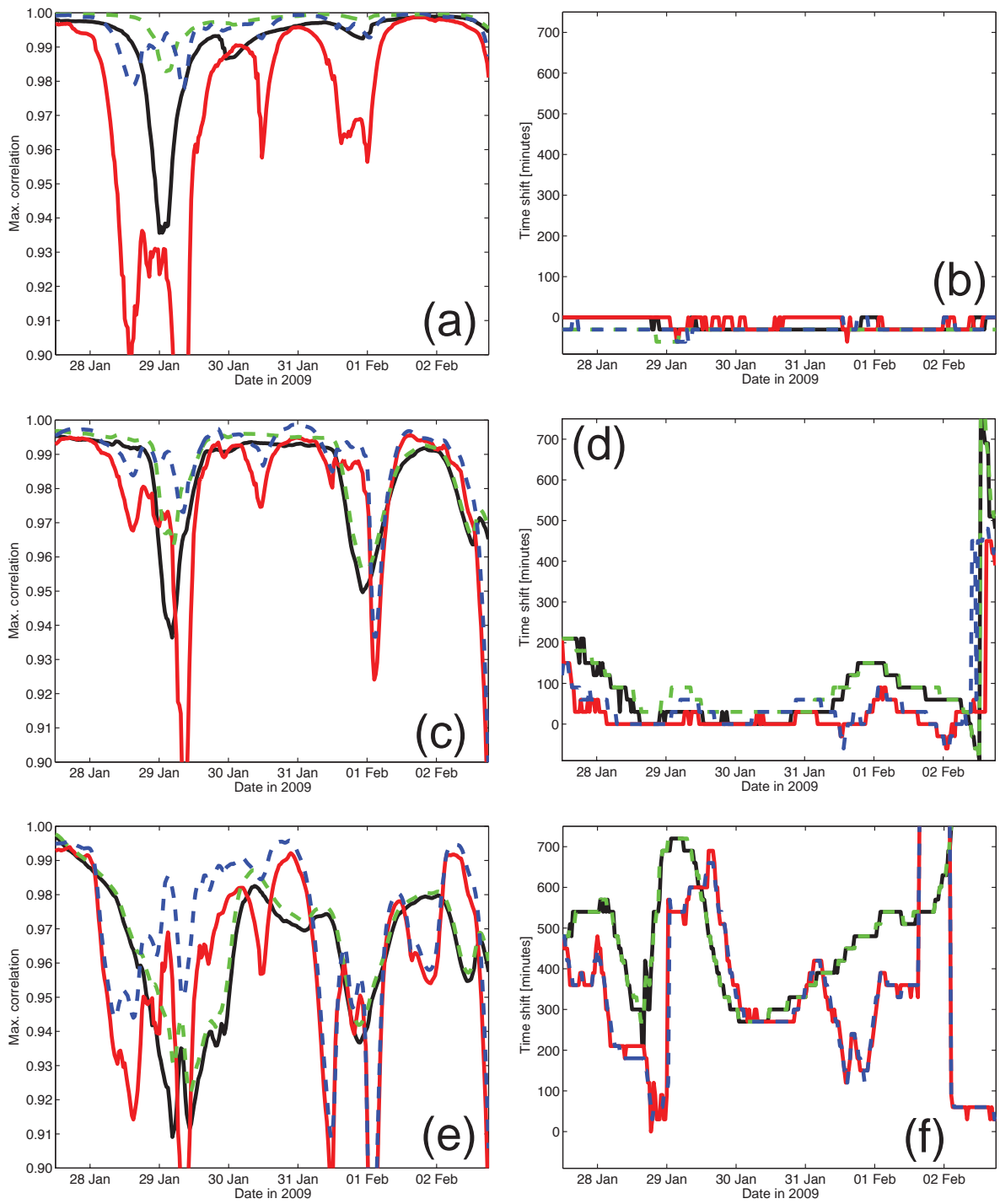

- $n=101 \longrightarrow n=101$, smoothed $--n=51$, smoothed

Figure 8. Epoch-wise maxima of correlation (left panels) and corresponding time shifts (right panels) for the three pairs of loggers T1 : T2 (top panels), T1: T3 (middle panels), and T1: T4 (bottom panels); for smoothing the centered moving mean of five samples was computed.

assumed. In our analysis of data collected in Schellenberger Eishöhle, correlation was generally high ( $>0.9$ for most of the time analyzed) and we can safely assume the linear model to be valid. The quality of the bias and scale parameters determined by a least-squares adjustment can be assessed by their formal errors. The overall quality of the model is characterized by the post-fit error of the modeled temperatures when compared to the ones actually observed.
The post-fit error $\sigma$ of the modeled temperatures is easily computed from the sum of squares of the residuals:

$$
\begin{aligned}
v^{2} & =\sum_{n}\left(\boldsymbol{T}_{\mathrm{B}, \text { observed }}-\boldsymbol{T}_{\mathrm{B}, \text { modeled }}\right)^{2} \\
\sigma & =\sqrt{\frac{v^{2}}{n-u}},
\end{aligned}
$$

with $n$ the number of observations used to fit the model (in our examples so far chosen to be equal to the number $n$ of samples used for the correlation analysis) and $u$ the number of unknown parameters estimated. The time shift is determined independently of bias and scale factor; nevertheless we chose $u=3$. 

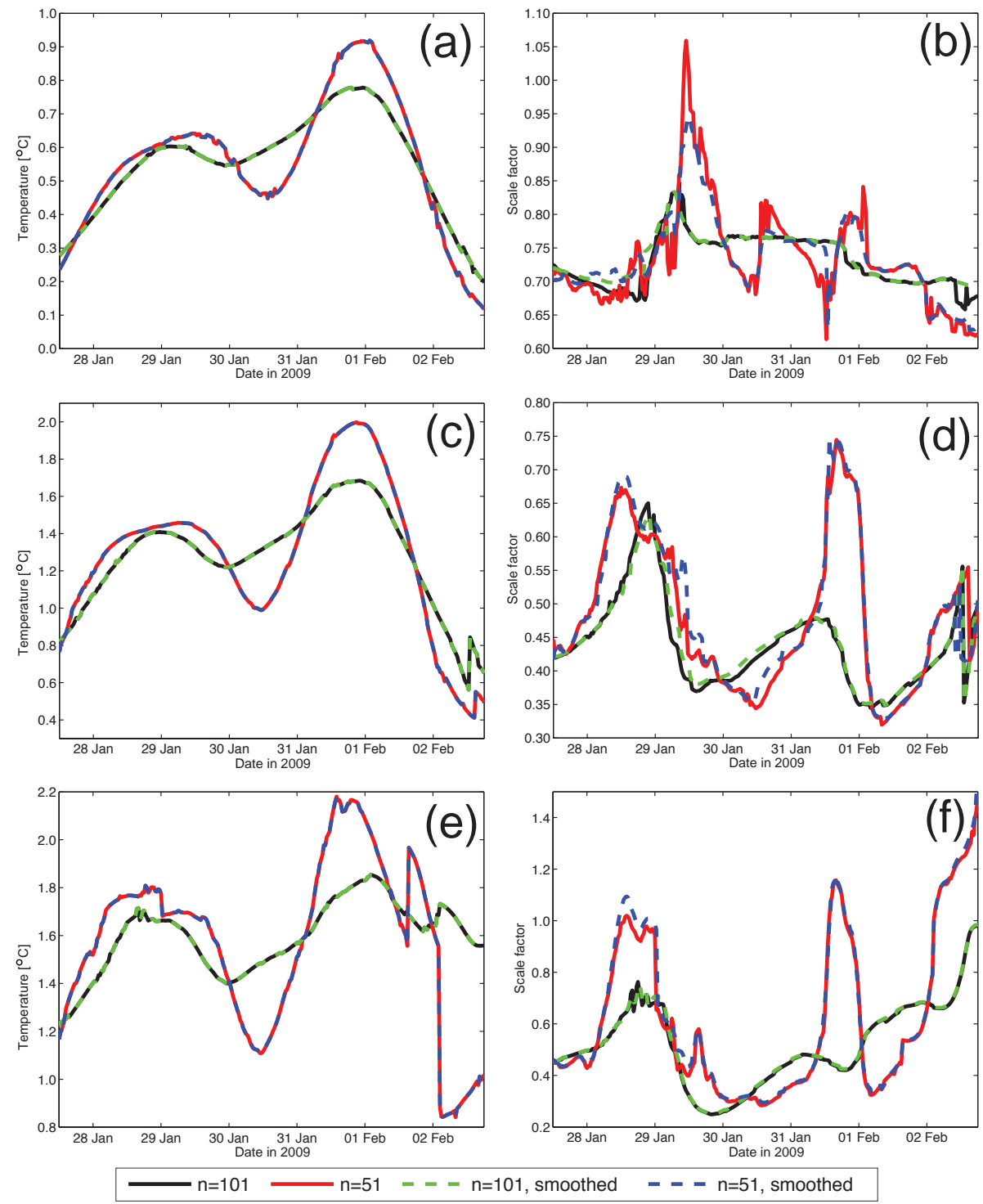

Figure 9. Epoch-wise biases (left panels) and scale factors (right panels) for the three pairs of loggers T1 : T2 (top panels), T1 : T3 (middle panels), and T1 : T4 (bottom panels); for smoothing the centered moving mean of five samples was computed.

The formal errors of bias $\sigma_{\mathrm{b}}$ and scale factor $\sigma_{\mathrm{s}}$ are taken from the covariance matrix of the least-squares adjustment:

$\mathbf{K}=\sigma^{2} \cdot\left(\begin{array}{cc}\sigma_{\mathrm{b}}^{2} & \sigma_{\mathrm{bs}} \\ \sigma_{\mathrm{sb}} & \sigma_{\mathrm{s}}^{2}\end{array}\right)=\sigma^{2} \cdot\left(\mathbf{A}^{T} \mathbf{P A}\right)^{-1}$

$\mathbf{K}$ is a symmetric matrix; covariances $\sigma_{\mathrm{bs}}$ and $\sigma_{\mathrm{sb}}$ are identical. Keep in mind that in Sect. 3 we chose $\mathbf{P}$ to be the identity matrix. The formal errors are scaled by the post-fit error $\sigma$. Note that from the covariance matrix one can also compute the correlation coefficient between the bias and the scale factor:

$r_{\mathrm{bs}}=\frac{\sigma_{\mathrm{bs}}}{\sqrt{\sigma_{\mathrm{b}} \cdot \sigma_{\mathrm{s}}}}$
This has not been evaluated in this study. In the case of the data analyzed from Schellenberger Eishöhle the correlation between bias and scale turned out to be small and could also be neglected (corresponding to a separate estimation of both parameters).

The formal errors of bias and scale factor, scaled with the post-fit error of the model, are shown in Fig. 10 for the time period analyzed in Sect. 5 . The temperature biases are rather well defined; the scale factors profit from a smoothing of the data. Rising errors to the end of the period correspond to the rising outside temperatures that finally lead to ceasing air movements in the cave and an interruption of the open period. 

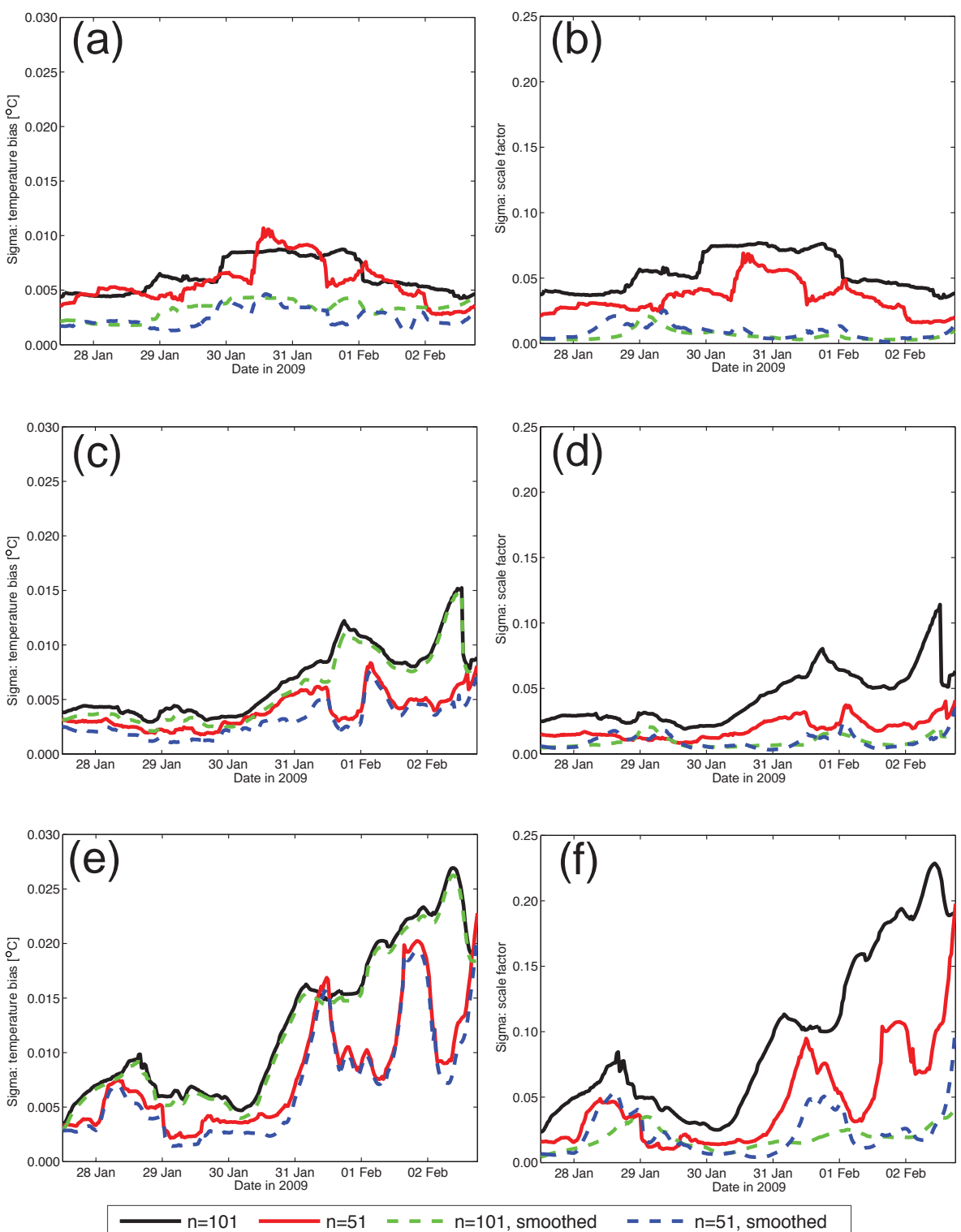

Figure 10. Epoch-wise standard deviations of biases (left panels) and scale factors (right panels) for the three pairs of loggers T1 : T2 (top panels), T1 : T3 (middle panels), and T1 : T4 (bottom panels).

As long as the time shifts are computed independently by cross-correlation we cannot define their error bounds correspondingly to bias and scale. However, in any case the accuracy of the determined time shifts is limited by the sampling rate of the temperature observations to half the sampling interval (in our case, this corresponds to error bounds of plus/minus $15 \mathrm{~min}$ ). Note that time shifts determined to be zero are not meaningless; they just show that the air took less time than half the sampling period (i.e., $15 \mathrm{~min}$ ) from one logger to another.

Finally the significance of the estimated parameters may be calculated, assuming that their errors are normally distributed (their variances are $\chi^{2}$-distributed). This test tells us if the parameter in question is indispensable to improve the model. We expect that during the closed phase, only the biases are significant parameters of the model (corresponding to time shifts of 0 and scales of 1 that do not contribute to the modeled temperatures), while during the open phase all three parameters are rated as significant. The test of significance will not tell us if the estimated values represent the physical quantities the parameters were intended to model. A parameter that absorbs systematic noise will be rated as significant, even if the determined numerical values may not be interpreted in a meaningful way.

To test the significance of the parameter in question, two different models are compared: one including all parameters 

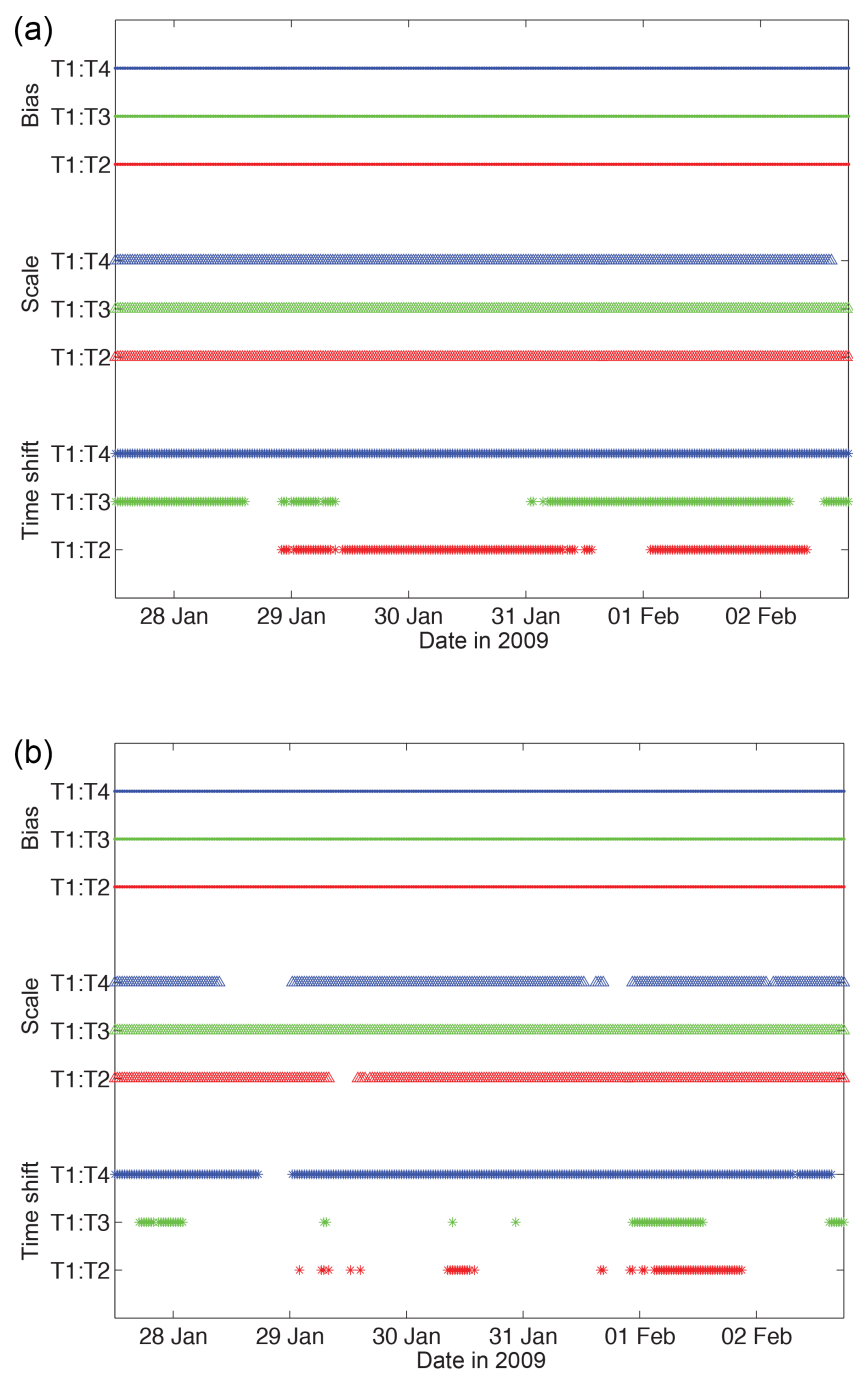

Figure 11. Significantly determined parameters; correlation length is 101 samples (a) or 51 samples (b).

(full model), the other one including all but the parameter in question (reduced model).

The reduced model to test the significance of $\Delta t$ reads

$T_{\mathrm{B}_{\Delta t}}(t)=s \cdot\left(T_{\mathrm{A}}(t)-\bar{T}_{\mathrm{A}}\right)+b^{*} ;$

the reduced model to test the significance of $s$ reads

$T_{\mathrm{B}_{s}}(t)=T_{\mathrm{A}}(t-\Delta t)+b^{*}$

and finally, the reduced model to test the significance of $b^{*}$ reads

$T_{\mathrm{B}_{b^{*}}}(t)=s \cdot\left(T_{\mathrm{A}}(t-\Delta t)-\bar{T}_{\mathrm{A}}\right)+\bar{T}_{\mathrm{A}}$.

Note that it is not correct to determine the parameters of the full model once and subsequently insert them into the reduced models. Instead, the parameters of each of the reduced models have to be determined in a separate estimation procedure to also take into account the correlations between the different parameters. As mentioned before, the correlations may be neglected here for the test of bias and scale, which can be determined quite independently, but for the significance test of the time shift, both parameters of the reduced model (Eq. 12) have to be re-estimated with a time shift of $\Delta t=0$.

We perform an $F$ test (e.g., Snedecor and Cochrane, 1989) computing the ratio

$\Phi=\frac{\left(v_{\mathrm{r}}^{2}-v_{\mathrm{f}}^{2}\right) /\left(r_{\mathrm{r}}-r_{\mathrm{f}}\right)}{v_{\mathrm{f}}^{2} / r_{\mathrm{f}}}$,

where $v_{\mathrm{r}}^{2}$ and $v_{\mathrm{f}}^{2}$ are the sum of squares of the observed temperatures after substraction of the modeled ones (see Eq. 8); subscript $f$ refers to the full model, subscript $r$ to the reduced model. $r_{\mathrm{r}}$ and $r_{\mathrm{f}}$ are the corresponding degrees of freedom $n-u$ of the two models, the number of unknowns $u_{\mathrm{r}}=u_{\mathrm{f}}-1$ of the reduced model being smaller than that of the full model $u_{\mathrm{f}}$, and therefore $r_{\mathrm{r}}=r_{\mathrm{f}}+1$.

$\Phi$ is $F$-distributed, its probability density function $F_{\mathrm{nm}}(\Phi)$, with $n=r_{\mathrm{f}}$ and $m=r_{\mathrm{r}}-r_{\mathrm{f}}$, is a measure for the probability that the additional parameter in the full model could have been estimated in the same way from normally distributed random numbers. We evaluate the associated cumulative distribution function and reject all parameters for which it is smaller than 0.99 (corresponding to a $99 \%$ confidence level). The remaining biases, scales, and time shifts are marked in Fig. 11a for a correlation length of 101 samples, and in Fig. 11b for a correlation length of 51 samples. Bias and scale turn out to significantly improve the model for most of the time. The results look different for the time shift, which is only rated as significant for short periods of time. Comparing Fig. 11 with Fig. 8 we realize that the time shift is always rated insignificant when it is estimated to be zero. This is reasonable because a time shift of zero corresponds to not estimating the time shift at all. As stated above, the estimates of zero for the time shift are artifacts caused by the coarse sampling rate. With an increased sampling rate, it can be expected that the time shifts are rated as significant whenever the scale factors that benefit from the high temperature resolution of the loggers indicate air movements in the cave. The message of Fig. 11 therefore is that for the time period analyzed, all three parameters - time shift (as soon as it is larger than half the sampling rate), bias, and scale - are indispensable for our model. The test probably will become more interesting when the model is refined to include effects like insolation of the entrance hall that most probably affects the loggers in Angermayerhalle and should be measurable, at least during the closed phase of the cave.

\section{Discussion of results}

The calcFLOW method proved very helpful to better understand the test data observed in Schellenberger Eishöhle. As 
described in Meyer et al. (2014), the two loggers T1 and T4 in Angermayerhalle show very different behavior (Fig. 7a) that could not yet be explained. Our analysis revealed a significant time shift (Fig. 7b) as well as a pronounced positive temperature bias (Fig. 7c) of T4 relative to T1, as well as a pronounced attenuation of the temperature variations (Fig. 7d) recorded by T4. We therefore assume that logger $\mathrm{T} 1$ records the cold inflowing air, while $\mathrm{T} 4$ records the relatively warmer air flowing out of the cave. We further assume that the cold inflowing air passes by logger $\mathrm{T} 2$ to the deepest point in Fuggerhalle, where logger T3 is positioned. Temperature biases are positive and increase with the distance the air has traveled into the cave (as long as we assume that T4 records the outflowing air), as predicted by our model. The scaling factors are smaller than 1 (attenuation of signal) and are inversely proportional to the distance the air has traveled.

The sampling rate of $30 \mathrm{~min}$ proved to be too coarse to determine the airflow speed from $\mathrm{T} 1$ to $\mathrm{T} 3$ for most of the time analyzed. The estimate of $0 \mathrm{~min}$ means that the air took less than $15 \mathrm{~min}$ for the distance of approximately $65 \mathrm{~m}$ between $\mathrm{T} 1$ and $\mathrm{T} 3$, corresponding to a speed of more than $4 \mathrm{mmin}^{-1}$ (agreeing well with air speeds of gravitational flow of $6 \mathrm{~m} \mathrm{~min}^{-1}$ reported by Smithson, 1991). Negative values for the time shift between $\mathrm{T} 1$ and $\mathrm{T} 2$ may indicate a position of logger T1 too high above the floor so that the cold air that flows along the floor of the passage passes T1 without being noticed and reaches $\mathrm{T} 2$ before it is recorded at $\mathrm{T} 1$. This suspicion was confirmed by in situ inspection of logger T1.

While T2 shows distinctive variations of rather short duration (and unknown origin) that clearly correspond to the temperature variations recorded by $\mathrm{T} 1$, the same variations are very much attenuated at $\mathrm{T} 3$ and not at all visible any more at T4. This may be explained by the distance the air traveled inside the cave and by the attenuation of the temperature variations due to energy exchange with stagnant cave air, ice, and rock. Moreover, Fuggerhalle acts as a dead end where the cold air that enters via Wasserstelle and probably also via Mörkdom is thoroughly mixed with the stagnant air. The assumption that Fuggerhalle is probably warmed by dynamic ventilation from deeper reaches of the cave could not be confirmed. The temperature biases and scaling factors determined for T3 fit our model very well. We conclude that Fuggerhalle is warmer than Angermayerhalle or Wasserstelle just because it is farther from the entrance.

From T3 at the furthest end of Fuggerhalle the warm air takes a significant amount of time before it reaches $\mathrm{T} 4$ on its way out of the cave. For this remaining distance of $115 \mathrm{~m}$, a time shift of $270 \mathrm{~min}$ was determined for our example epoch (Sect. 4.1), corresponding to an air speed of $0.5 \mathrm{~m} \mathrm{~min}^{-1}$. Not much more signal attenuation or warming takes place along this path. Unfortunately, in the time period analyzed, no logger was positioned in the second passage (Mörkdom) connecting Angermayerhalle and Fuggerhalle, so it cannot be clarified if one of the passages acts as the primary way down for the cold air while the other channels the warm air back to the surface. The determined air speeds have to be considered as mean speeds for the way the air traveled between loggers; they will of course vary depending on the cross section of the passage. The different speeds determined for the inflowing cold air and the replaced warm air may also be explained by the cross section of the passage occupied by the corresponding air flow. Independent of all the factors that complicate interpretation, we can state that the results appear to be realistic.

The resolution of the correlation analysis is drastically limited by the coarse sampling rate of the loggers and the missing synchronization. This fact does not reduce the applicability or validity of our model, but it limits the interpretation of the results. Nevertheless we were able to characterize the general patterns of air movement and their slow temporal variations. The analysis of the temporal variability of the determined parameters (Sect. 5) confirmed the basic principles on which the model is based. Low outside temperatures correspond to steep temperature gradients that result in small time shifts (high air speeds). The energy exchange with the cave environment is limited by the short time the cold air stays in the cave, and the attenuation factors are closer to 1 when outside temperatures are low. The biases correspond to the temperature gradients and are larger during spells of cold weather.

But the analysis of the temporal variability also revealed problems in the correlation analysis. The cross-correlation of loggers T1 and T4 exhibits an unrealistic variability, including a number of jumps. These clearly are artifacts that are caused by side maxima of the correlation analysis, stressing the need to limit the search window to a sensible width, which depends on the cave, the placement of the loggers, and the distance between loggers, and can only be refined after some tentative analysis. Generally it can be stated that times of poor correlation correspond to periods of little temperature variations. Long correlation lengths may help but also reduce the time resolution of the determined time shifts due to averaging over the number of samples used for the correlation analysis. A rise of the outside temperatures above the cave temperature will lead to ceasing air flow and an interruption in the open phase of the cave. In this case the correlation analysis fails.

The determination of biases is robust, while the determination of scaling factors is only limited by the signal-tonoise ratio of the observations. The time series of $\mathrm{T} 1$ and $\mathrm{T} 2$ show a number of short-term variations superimposing the long-term variations of the outside temperature. They cannot be explained by our simple model and hinder the estimation of scale factors for logger pair T1/T2. Smoothing helps to separate the long-term from the short-term variations and stabilize the estimated scale factors. A better solution surely would be to find the reason for the short-term temperature variations and include corresponding parameters in the model; the forcing of air into the entrance hall by out- 
side winds would be a probable candidate, though difficult to model. As is the case for the time shifts, a reduced number of samples used for the determination of bias and scale factor leads to an improved time resolution, while an increased number of samples stabilizes the estimation. As can be expected, the uncertainty of the fit (i.e., the formal errors of bias and scale factor) increases with the distance between loggers.

\section{Conclusions}

The objective of this paper is to present the principles and the methodology of the calcFLOW method that was developed in order to be able to use air temperature measurements in static ice caves to define the airflow regime. The idea of calcFLOW is based on the fact that in many ice caves in remote places, airflow measurements are difficult. However, in every ice cave where cave climate related studies are conducted, at least temperature measurements (air, rock, ice) are performed. Based on this data we calculate three different parameters to better characterize the processes that dominate the cave climate and to understand the temperature differences observed between the measuring points: the airflow speed, the change of the mean air temperature, and the attenuation of the temperature variations dependent on the location inside the cave. The primary objective is to calculate airflow speeds inside a static ice cave to define the airflow regime. It is achieved by cross-correlating air temperature data of different logger sites. The method was applied to temperatures recorded in Schellenberger Eishöhle during the open period, when air movement inside the cave is governed by gravitational flow.

The method of cross-correlation we use for the determination of time shifts in general depends on rather distinctive temperature variations to successfully correlate the observations of different loggers. On the other hand, the airflow speed is supposed to be relatively constant during the time span used for correlation. These two requirements contradict each other and it has to be shown by further studies to what extent the temporal variability of the air movements inside the cave may be resolved. Most probably the reliability of the analysis will benefit from an increased sampling rate of the temperature observations. Regardless of the complexity of the situation at our test site, we may state that the presented method is well suited to uncover the complicated air movements in the cave. The results of the analysis will help to optimize the placement of the loggers. An increased number of loggers positioned near the floor as well as near the ceiling of the passages will allow the paths of the inflowing and outflowing air to be distinguished with much better spatial resolution and reliability. Decreased sampling intervals will enable the determination of the speed of the rather fast inflowing cold air and generally improve the reliability of the correlation analysis.
We have already tested calcFLOW with air temperature data from Fossil Mountain Ice Cave (USA), but these results will be part of future publications. What we can already state for the moment is that calcFLOW is applicable to other ice caves, too. This is one major reason for the publication of this pilot study and also a reason for us to keep the model as simple as possible. We want to present a basic tool for cave climate studies which everyone can use for their specific site. To summarize the outcome of this study, we can state that calcFLOW is useful in the following way:

1. to characterize the airflow regime inside a static ice cave;

2. to compute (interpolate) the temperatures between two loggers with one simple model, based on only three determined parameters;

3. to indicate possible problems in the measuring setup (e.g., position and height of loggers); and

4. to indicate useful observation intervals.

In a next step we will address key problems of calcFLOW in a dedicated simulation study with the objective to provide measures for the signal content of the time series of temperature observations, evaluated by the root-mean-square, and for the quality of the cross-correlation. The latter will be based on the shape of the peak of maximum correlation, exploiting characteristics like its dominance and width. The simulation study will also provide a test bed for cross-validation methods to assess the reliability of the determined air speeds; and of course we also hope to validate the calculated airflow speeds by comparison to real-time airflow measurements.

Meanwhile the logger setup in Schellenberger Eishöhle has been revised. With the expected results we hope to be able to further differentiate the specific paths of the airflow and to tackle questions of energy exchange in the cave. For this task, finally a much denser network of temperature loggers, which also probe ice and rock temperatures, and a volume model of the cave and its ice filling, will be indispensable. The evaluation of the temperature observations has to be automatized, based on the criteria developed in the simulation study.

Acknowledgements. This work is part of the Italian Project of Strategic Interest NEXTDATA (PNR2011-2013) funded by the Italian National Research Council (CNR). It is also part of a $\mathrm{PhD}$ project, "Ice deposit evolution and cave climatology of ice caves", at Ruhr University Bochum (Germany). For the logistical support and the good cooperation, we would like to thank the Verein für Höhlenkunde Schellenberg e.V. Moreover, we would like to thank Martina Grudzielanek for the revision of the mathematical part of the paper.

Edited by: M. van den Broeke 


\section{References}

Bock, H.: Mathematisch-physikalische Untersuchung der Eishöhlen und Windröhren, in: Die Höhlen im Dachstein, Verein für Höhlenkunde in Österreich, Graz, 102-144, 1913.

Bögli, A.: Karsthydrographie und physische Speläologie, Berlin, 1978.

Crammer, H.: Eishöhlen- und Windröhren-Studien, in: Abhandlungen der K. K. geographischen Gesellschaft in Wien, Vol. 1, K. K. geographical society of Vienna, printed by Verlag Lechner, Wien, 1899.

Fugger, E.: Beobachtungen in den Eishöhlen des Untersberges bei Salzburg, Mitteilungen der Gesellschaft für Salzburger Landeskunde (MGSLK), Salzburg, 28, 65-144, 1888.

Grebe, C.: Eishöhlenforschung vom 16. Jahrhundert bis in die Moderne - vom Phänomen zur aktuellen Forschung, MS thesis, unpublished, Bochum, Germany, 2010.

Grebe, C., Ringeis, J., and Pflitsch, A.: Study of Temperature and Airflow in the Schellenberger Ice Cave (Berchtesgadener Limestone Alps, Germany), in: Proceedings of 3rd International Workshop on Ice Caves (IWIC-III), Kungur Ice Cave, Perm Region, Russia, 12-17 May 2008, 26-29, 2008.

Koch, K. R.: Parameter Estimation and Hypothesis Testing in Linear Models, 2nd Edn., Springer, Berlin, Heidelberg, New York, 1999.

Korzystka, M., Piasecki, J., Sawinski, T., and Zelinka, J.: Climatic system of the Dobinska Ice Cave, in: Proceedings of the 6th Congress International Show Caves Associations, Liptovsky Mikulas, 85-97, 2011.

Laroque, M., Mangin, A., Razack, M., and Banton, O.: Contribution of correlation and spectral analyses to the regional study of a large karst aquifer (Charente, France), J. Hydrol., 205, 217-231, 1998.

Lohmann, H.: Das Höhleneis unter besonderer Berücksichtigung einiger Eishöhlen des Erzgebirges, Diss., Univ. Leipzig, Leipzig, 1895.

Lütscher, M. and Jeannin, P. Y.: Une anne d'enregistrements de temperatures la glaciere de Monlesi/Ein Jahr Temperaturmessungen in der Glaciere de Monlesi (NE), Stalactite, 52, 27-29, 2002.

Lütscher, M. and Jeannin, P. Y.: A process-based classification of alpine ice caves, Theor. Appl. Karstol., 17, 5-10, 2004 a.

Lütscher, M. and Jeannin, P. Y.: The role of winter air circulation for the presence of subsurface ice accumulations: an example from Monlesi Ice Cave (Switzerland), Theor. Appl. Karstol., 17, 19$25,2004 b$.
Lütscher, M.: Processes in Ice Caves and their Significance for Paleoenvironmental Reconstructions, Thesis university of Zürich, edition ISSKA, La Chaux-de-Fonds, 2005.

Meyer, C., Pflitsch, A., Holmgren, D., and Maggi, V.: Schellenberger Ice Cave (Germany): a conceptual model of temperature and airflow, in: Proceedings of the Sixth International Workshop on Ice Caves, 17-22 August, Idaho Falls, Idaho, USA, 82-87, 2014.

Morard, S., Bochud, M., and Delaloye, R.: Rapid changes of the ice mass configuration in the dynamic Diablotins ice cave Fribourg Prealps, Switzerland, The Cryosphere, 4, 489-500, doi:10.5194/tc-4-489-2010, 2010.

Padilla, A. and Pulido-Bosch, A.: Study of hydrographs of karstic aquifers by means of correlation and cross-spectral analysis, J. Hydrol., 168, 73-89, 1994.

Pflitsch, A. and Piasecki, J.: Detection of an airflow system in Niedzwiedzia (Bear) Cave, Kletno, Poland, J. Cave Karst Stud., 65, 160-173, 2003.

Pflitsch, A., Piasecki, J., and Sawinski, T.: Development and degradation of ice crystals sediment in Dobsinska Ice Cave (Slovakia), in: 2nd International Workshop on Ice Caves IWIC II, Proceedings, 8-12 May, Demänovska Dolina, Slovak Republic, Liptovsky Mikulas, 29-37, 2007.

Racovitza, G.: Observations sur la glacière naturelle dite Ghetarul de la Scarisoara', Bull. Soc. Sci. Cluj., III, 75-108, 1927.

Racovitza, G.: La classification topoclimatique des cavités souterraines, in: Trav. Inst. Speol. "E. Racovitza”, 14, 197-216, 1975.

Racovitza, G. and Onac, B. P.: Scarisoara Glacier Cave, Monografic study, Ed. Carpatica, Cluj-Napoca, 2000.

Saar, R.: Eishöhlen, ein meteorologisch-geophysikalisches Phänomen, Untersuchungen an der Rieseneishöhle (R.E.H.) im Dachstein, Oberösterreich, in: Geogr. Ann. A, 38, 1-63, 1956.

Smithson, P. A.: Inter-relationship between cave and outside air temperatures, Theor. Appl. Climatol., 44, 65-73, 1991.

Snedecor, G. W. and Cochrane, W. G.: Statistical Methods, 8th Edn., Iowa State University Press, Ames, 1989.

Thury, M.: Etudes sur les glacières naturelles par M. Thury, Tiré des Archives des Sciences de la Bibliothèque Universelle, Genève, 1861 . 